\title{
Racionalidade musical e experiência natural formativa em Rousseau
}

\section{Musical rationality and formative natural experience in Rousseau}

\author{
Raimundo Rajobac ${ }^{1}$ \\ Claudio A. Dalbosco ${ }^{2}$
}

\begin{abstract}
RESUMO
O estudo tem como objetivo investigar o estatuto da racionalidade melódica no Ensaio sobre a origem das línguas de Rousseau na busca por articular o fazer musical no ocidente com problemas epistemológicos característicos da racionalidade iluminista, pondo em foco as concepções sobre a educabilidade humana e suas respectivas formas de experiências formativas inseridas no amplo processo de relação tensional entre expressão musical e formas de racionalidade. Após a apresentação da hipótese e problema de pesquisa, três passos fundamentais serão desdobrados: o primeiro analisa o significado epistemológico do Ensaio como crítica à episteme cartesiana. O segundo reconstrói a concepção rousseauniana de música, atendo-se na melodia como seu princípio básico. O terceiro e último apresenta uma reconstrução esquemática da distinção entre razão perceptiva e razão intelectual, pondo em foco a arquitetônica pedagógica do Emílio, e o lugar que nela ocupa a educação natural, sustentada pela razão perceptiva como base da educação do corpo e do refinamento dos sentidos.
\end{abstract}

Palavras-chave: racionalidade; educação; música; melodia; formação.

\begin{abstract}
This study aims at investigating the statute of the melodic rationality in Rousseau's Essay on the Origin of Languages in the search for articulating
\end{abstract}

DOI: $10.1590 / 0104-4060.36002$

1 Universidade Federal do Rio Grande do Sul. Porto Alegre, Rio Grande do Sul, Brasil. Rua Senhor dos Passos, 248. Centro. CEP: 90040-390.

2 Universidade de Passo Fundo. Passo Fundo, Rio Grande do Sul, Brasil. - CNPq. BR 285, São José. CEP: 99052-900. 
the making of music in the west with epistemological problems, typical in the illuminist rationality, focusing on the conception of human educability and its respective forms of formative experiences inserted in the broad process of a tensional relation between musical expression and forms of rationality. After the introduction of the hypothesis and research problem, three main steps will be unfolded: the first analyses the epistemological meaning of the Essay as criticism to the Cartesian episteme. The second rebuilds Rousseau's conception of music, abiding in the melody as its basic principle. The third and last step presents a schematic reconstruction of the distinction between perceptive reasoning and intellectual reasoning, focusing on the pedagogical architectonics of Emile, and the position taken by the natural education, supported by the perceptive reasoning as the basis for the education of the body and the refinement of the senses.

Keywords: rationality; education; music; melody; formation.

\section{Introdução}

A investigação do estatuto da racionalidade melódica no Ensaio sobre a origem das línguas ${ }^{3}$ de Rousseau articula o fazer musical com problemas epistemológicos característicos da racionalidade iluminista e orienta à posição da melodia no contexto da crítica rousseauniana em relação ao conceito de razão iluminista ${ }^{4}$. Tais preocupações exigem, inicialmente, o questionamento sobre o que significa compreender o fazer musical no ocidente numa perspectiva epistemológica, bem como as implicações formativas e pedagógicas que a ele estão relacionadas. A centralidade desse questionamento reside em estabelecer pontos de interlocução entre práticas, fazeres e criações em música, com temáticas filosóficas mais amplas que delinearam perspectivas alicerçadas em revoluções paradigmáticas, as quais marcaram, por sua vez, a própria história do conhecimento ocidental.

3 Doravante citado somente como Ensaio. Publicado em 1781, em Paris, por Peyrou. A data de redação do escrito tem sido alvo de grandes discussões. Catherine Kintzler, Starobinsky e Derrida tornaram-se fontes determinantes para investigações sobre essa questão. Ressalta-se ainda a significativa ligação do Ensaio com o Discurso sobre a origem e os fundamentos da desigualdade entre os homens (Segundo Discurso).

4 Entendemos por razão iluminista a razão moderna vincula à filosofia da consciência, cujo principal expoente é o filósofo francês René Descartes. Contudo, o Iluminismo é um amplo movimento intelectual, que envolve várias tradições, autores e textos, os quais, de modo algum, são consensuais entre si. Para uma visão introdutória e de conjunto sobre o iluminismo, consultar W. Schneiders (2008). 
Essa perspectiva geral confere as condições de desenvolvimento do presente ensaio à medida que nos permite discutir sobre música, racionalidade iluminista e experiência formativa em uma constante e interdependente relação. Aponta-se, portanto, a uma racionalidade musical que comporta em si conflitos epistemológicos profundos que marcaram nossa tradição desde aquele conflito mitológico entre Apolo e Mársias até as rupturas e continuidades da música do século XX, bem como para as diferentes concepções sobre a educabilidade humana e seus respectivos modos de experiências formativas inseridas nesse amplo processo de relação tensional entre expressão musical e formas de racionalidade.

Desde a conhecida concepção platônica da música sob influência pitagóri$\mathrm{ca}^{5}$, bem como a influência que esta e o próprio pitagorismo exerceram sobre a tratadística medieval, e todo o contexto mais amplo que concorrerá para a Renascença e o consequente Século das Luzes, são apresentados conflitos profundos de racionalidades - e seus visíveis efeitos na ampla problemática da formação humana-, com os quais, as artes em geral, e em nosso caso específico a música, comunicaram-se mutuamente. Nesse sentido, o projeto filosófico-musical de Rousseau, o qual incorpora em parte a crítica às pretensões da racionalidade iluminista, representa um momento central, na medida em que não só se configura como crítica à perspectiva epistemológica do projeto iluminista, como também ao ideal de formação humana a ele subjacente. Como iremos defender logo abaixo, à crítica da "racionalidade" musical harmônica vinculam-se preocupações não só de natureza epistemológica, mas, sobretudo - quando se tem diante dos olhos o Émile ou de l'éducation ${ }^{6}$-, também de natureza nitidamente pedagógica, relacionada ao amplo processo formativo e educacional humano.

5 Uma hermenêutica aprofundada desse processo pode ser encontrada em Max Weber (1995), para quem nossa música harmônica de acordes racionalizou o material sonoro mediante a divisão aritmética, e respectivamente harmônica. Quando houve uma transposição de intervalos da flauta para a cítara, procurou-se racionalizá-los, e disto resultou a controvérsia sobre a natureza dos intervalos, sempre levada adiante pelos teóricos posteriores. Assim, o racionalismo dos reformadores da música, proveniente da teoria matemática, trabalhou sem cessar e das formas mais variadas no ajustamento das discrepâncias resultantes da assimetria da oitava. Entenda-se porque a tendência por parte da música, a repetição dos mesmos motivos com outras palavras, e a construção, por parte da língua, de estrofes de uma canção com melodias constantes, são fatores que acabam por romper essa espécie de unidade da fala com a melodia [Melos]. Entre os helenos, esta unidade desaparece inteiramente com o desenvolvimento da linguagem como instrumento retórico, levando, com isso, à concomitante decadência do acento musical. Na verdade, a formulação de Rameau de que o "baixo fundamental", isto é, o som harmônico fundamental dos respectivos acordes, pode mover-se apenas nos intervalos dos acordes de três sons (quintas justas e terças), submete também a melodia à harmonia de acordes racional. Ver ainda Nietzsche, O nascimento da tragédia, 1993 e $O$ drama musical grego, 2005.

6 Emílio ou da Educação. Doravante abreviado como Emílio. 
Lê-se no Ensaio: “[...] a música [...] não é a arte de combinar sons de uma maneira agradável ao ouvido. Se fosse apenas isso, [...] pertenceria às ciências naturais e não às belas artes" (ROUSSEAU, 2008, p. 151). Essa citação anuncia questões diversas que perpassam o todo da obra em estudo. Rousseau pontua a crítica ao conceito de música iluminista, principalmente aquele difundido pelo Ancien Régime do qual Jean-Philippe Rameau firmou-se como principal representante ${ }^{7}$. Ao assumir essa posição, o genebrino lançou duros golpes ao conceito reduzido de razão que orientou as especulações iluministas, ao entendimento a respeito da natureza, das artes, da sociedade e da cultura como um todo, incluindo nela, como aspecto privilegiado, o próprio problema da educabilidade humana. No que diz respeito especificamente à música, há a recusa rousseauniana ao primado da arte agradável e combinatória de caráter mecânico e matematizante ${ }^{8}$. Daí a necessidade do estabelecimento de fronteiras entre ciências naturais e belas artes, posto que todo o ideal mecânico-matematizante, principalmente a teoria harmônica de Rameau, associa a música ao exercício reflexivo e a distancia dos sentimentos, das paixões. É a partir desse contexto que se faz possível nossa investigação, a qual propõe tematizar o resgate da melodia por Rousseau enquanto problema de racionalidade e, por isso mesmo, também como um problema de formação humana.

Nesse contexto, nosso problema de investigação consiste em saber, por um lado, em que sentido a racionalidade melódica do Ensaio significa uma crítica à epistemologia iluminista, sobretudo, de matriz cartesiana e, por outro, que relações tal crítica mantém com o ideal formativo inerente ao projeto de educação natural do Emílio. Como se pode observar, imbricam-se mutuamente, em nosso problema, três grandes esferas da cultura humana: arte, epistemologia e educação. Para tratar de tal problema, partiremos da hipótese de que o interesse de Rousseau pela música e a crítica à racionalidade iluminista a ela subjacente também estão na base de sua crítica à éducation barbare de sua época. Ou seja, a concepção rousseauniana de música auxilia esclarecer, por um lado, o nexo estreito entre epistemologia moderna, de corte cartesiano, e o ideal educacional e formativo a ela vinculado e, por outro, a compreender melhor as razões que levam o genebrino a colocar a razão perceptiva na base de seu projeto de educação natural, esboçado nos três primeiros livros do Emílio. Trata-se, com isso, no fundo, de reposicionar o papel dos sentimentos e emoções (paixões) no âmbito do conhecimento humano, em sentido amplo e, especificamente, no que se refere à experiência formativa.

7 Ver: MARQUES, J. O. A. Rousseau, Rameau e o Ensaio sobre a origem das línguas, 2010.

$8 \mathrm{Na}$ tradição filosófica racionalista germânica, Gottfried Wilhelm Leibniz marcou época com Dissertatio de arte combinatória (1666). 
Do ponto de vista da delimitação textual, a problemática acima referida exige que nos concentremos em determinados capítulos do Ensaio e em algumas passagens do Emílio: do primeiro interessa-nos especialmente o capítulo XII em diante e, do Emílio, algumas passagens inseridas nos três primeiros livros. Como nossa pesquisa é de natureza eminentemente bibliográfica, o problema da compreensão do texto e da relação entre autor e leitor assume importância decisiva. Nossa dificuldade aí aumenta muito considerando o caráter extraordinariamente paradoxal que Rousseau como autor atribuiu conscientemente aos seus escritos. Vale, aqui, para o escritor de genebra, talvez mais do que qualquer outro autor, o credo gadameriano de que é preciso saber quanto fica de não dito quando se diz algo. É justamente nesse contexto que emerge a compreensão como problema hermenêutico fundamental e que certamente ilumina o difícil problema da relação entre autor e leitor na investigação do sentido do texto9.

$\mathrm{Na}$ sequência, trataremos do problema e da hipótese acima referidos desdobrando nossa argumentação em três momentos interligados entre si. No primeiro, analisamos brevemente o significado epistemológico do Ensaio como crítica à episteme cartesiana. Com isso, pretendemos deixar claro o valor histórico, filosófico e pedagógico desse escrito, que denuncia, com todas as letras, ainda no século XVIII, os limites da razão analítica (apodítica dedutiva), deixando manifesto, nas entrelinhas, o quanto é indispensável, para pensar a razão humana em sua amplitude, considerá-la na multiplicidade de suas vozes.

No segundo momento, reconstruímos a concepção rousseauniana de música, atendo-nos na melodia como seu princípio básico. A crítica que Rousseau faz à harmonia e sua defesa da melodia elucida, no âmbito musical, sua crítica mais

9 Hans-Georg Gadamer insere a compreensão, em Verdade e Método, na conversação que o leitor estabelece com o texto legado pela tradição. Esclarece, contudo, que um texto só pode dizer algo em razão das perguntas que o leitor for capaz de lhe fazer. Nesse contexto, a compreensão sintetiza a manifestação mais apurada da relação tensional entre pergunta e resposta, a qual, por sua vez, é considerada como núcleo da experiência hermenêutica enquanto conversação. O próprio Gadamer resume isso em uma passagem da referida obra: "Pois a dialética da pergunta e resposta que temos descoberto permite que a relação da compreensão se manifeste como uma relação recíproca à maneira de uma conversação" (GADAMER, 1999, p. 383; grifos e tradução nossos). Dito de outro modo, a compreensão nada mais é do que a dialética entre pergunta e resposta que se constrói na conversação autêntica entre autor e leitor na busca pelo sentido do próprio texto. Conversação assume aqui um duplo sentido interligado entre si: a disposição de escutar o sentido do texto, orientando-se por perguntas que precisam ser constantemente reformuladas. Essa dupla significação da escuta e da pergunta exige, no âmbito de nossa relação com o texto rousseauniano, a abertura para ouvir o texto e poder, com isso, não só perceber seu sentido aparente, mas também perscrutar aquilo que permanece oculto no que é dito. Também exige, considerando nosso problema de investigação, buscar o vínculo entre problemas e conceitos que não foram estabelecidos claramente pelo próprio autor. Em síntese, o aporte hermenêutico nos auxilia duplamente: na construção da necessária abertura à escuta do texto e, mediado pela pergunta, ir além do próprio sentido do texto. 
ampla à episteme iluminista, assinalando também seu distanciamento em relação aos philosophes. Como a defesa da melodia significa um reposicionamento das paixões no âmbito geral da cognição humana, ela torna-se indispensável para compreender o papel que Rousseau atribui à razão perceptiva no âmbito de sua educação natural.

O nexo entre razão perceptiva e educação natural é o tema com o qual nos ocupamos na terceira e última parte do ensaio. Iniciamos com uma breve reconstrução esquemática da distinção entre razão perceptiva e razão intelectual, mostrando que o primado concedido por Rousseau à razão perceptiva no processo formativo do ser humano em sua fase infantil não significa sua adesão ao sensualismo ingênuo. Ao contrário disso, Rousseau tem clareza de que se a experiência baseada nas sensações é o ponto de partida do conhecimento e da aprendizagem, ela não pode ser o seu ponto de chegada. Na sequência, depois de reconstruir brevemente a arquitetônica pedagógica do Emílio, localizando o lugar que nela ocupa a educação natural, procuramos evidenciar o quanto a "física experimental" sustentada pela razão perceptiva está na base da educação do corpo e do refinamento dos sentidos. Ora, justamente por compreender que as paixões e os sentimentos possuem valor indispensável à experiência formativa humana, especialmente à formação da criança, é que Rousseau pôde estabelecer epistemologicamente a razão perceptiva como núcleo da educação natural.

\section{Da crítica à episteme cartesiana}

O problema que está implicado nessa temática possui um alcance atual ao campo educacional muito maior do que inicialmente podemos imaginar. $\mathrm{O}$ que já está em jogo na crítica de Rousseau, a episteme moderna, nada mais é do que sua própria crítica à razão reduzida ao modelo da mathesis universalis. Tal modelo, elaborado inicialmente pelos grandes sistemas metafísicos do século XVII - sobretudo o sistema cartesiano, embora devêssemos incluir aí também Spinoza e Leibniz -, ainda vigorava com muita força no próprio século de Rousseau. A matemática universal, que deveria servir de modelo a todos os outros saberes humanos, incluindo a arte e a educação, baseava-se em uma razão analítica de cunho apodítico dedutivo. Ou seja, formulava-se um teorema, constituído por um princípio geral ou por vários princípios e buscava-se deduzir todos os raciocínios subsequentes deste princípio geral.

Quanto mais irrefutável se demonstrasse tal princípio, mais seguro seria o sistema dele derivado. A verdade dependia então de um princípio de fundamen- 
tação última e, sendo assim, não seria obviamente na esfera dos sentidos que tal princípio deveria ser buscado. O Discurso do Método torna-se ilustrativo, inclusive pedagogicamente, de uma biografia filosófica moderna, eminentemente racionalista, que procura angustiada e obcecadamente pelo princípio último que daria segurança ao sistema de pensamento. No percurso estabelecido pela dúvida, Descartes procura se independizar da tradição intelectual na qual foi formado e, depois de procurar e também não encontrar no grande livro do mundo a certeza de que precisava, volta-se meditativamente para o interior de seus próprios pensamentos. Toma consciência de que enquanto duvidava de tudo, pondo em dúvida o conhecimento de seus mestres e a verdade da cultura do mundo, não poderia mais duvidar ao menos de uma coisa, a saber, de que continuava pensando enquanto duvidava. Chega então à certeza do cogito como condição de sua própria existência: cogito ergo sum (penso, logo existo).

Não nos interessa aqui seguir de perto o refinamento filosófico que a argumentação metafísica de Descartes assume para justificar seu sistema, tampouco analisar todas as dificuldades nas quais tal argumentação se enreda ${ }^{10}$. Importa, sim, destacar que a fundação do cogito ocorre com base no dualismo entre coisa pensante e coisa material, que é, por sua vez, herdeira da ampla tradição racionalista ocidental, remontando sua origem no dualismo platônico entre corpo e alma. Nesse contexto, o reducionismo da razão surge exatamente quando a natureza da coisa pensante é justificada, ao menos no modo de segurança e certeza pretendido por Descartes, somente se os sentidos e tudo aquilo que pertencer ao âmbito da coisa extensa forem devidamente isolados. O que fica claro, então, nesse movimento de pensamento, é que a certeza do cogito só pode ser conquistada mediante o empobrecimento da coisa extensa, tendo, como uma de suas consequências, a exclusão dos sentidos. Nesse ponto, o racionalismo cartesiano torna-se mais radical do que o Platão do Teeteto, pois o filósofo grego foi cuidadoso o suficiente para não descartar a esfera da doxa como um problema legítimo do conhecimento humano. Platão foi levado, nesse sentido, a elaborar um amplo programa investigativo, visando estabelecer, no referido Diálogo, o lugar e o papel das percepções no âmbito do conhecimento humano.

Com sua forma de pensar, Descartes fomentou a educação de cunho marcadamente racionalista. Ou seja, da estrutura do cogito brotou aquele ideal educativo iluminista que encontra seu centro na razão analítica, de cunho apodítico e dedutivo. Baseando-se apenas em princípios universais, tal educação

10 A filosofia contemporânea, sobretudo depois de Nietzsche, volta-se cada vez mais de modo crítico à filosofia cartesiana, concebendo-a como paradigma fundante do discurso filosófico moderno. Na atualidade, tanto Jürgen Habermas (1997) como Michel Foucault (2004) são, cada um a seu modo, figuras exemplares da crítica à "verdade cartesiana". 
enquadra o particular no universal, deixando de apreender a singularidade e, com isso, de enxergar a diferença. Como é uma educação eminentemente intelectualista, pretende raciocinar desde cedo com a criança, desconsiderando suas condições afetivas e cognitivas próprias. Em síntese, é uma educação livresca que se baseia estritamente na autoridade do mestre e no seu discurso racionalista, inclusive, concedendo ao adulto o poder absoluto de determinar o futuro das novas gerações (DURKHEIM, 1975). Nesse sentido, o autoritarismo inerente ao intelectualismo pedagógico impede o sentido genuíno da própria ideia de educação como manifestação do novo que cada criança traz ao vir ao mundo (ARENDT, 1994, p. 255-276). No intelectualismo pedagógico, repousa o sentido conservador e não conservativo de educação.

Mas, como Rousseau se posiciona frente a essa tradição racionalista? O problema apresentado pelo genebrino no Ensaio faz frente à tradição cartesiana ao ligar a música à sensibilidade e às paixões e não apenas ao cogito, e apresenta como novidade filosófica à concepção de linguagem clássica cartesiana o elemento musical: a melodia. Sabe-se da decidida crença de Descartes na matemática e o quanto esta determinou sua concepção de música, já na juventude, com a obra Compendium Musicae, de 1618. Aqui, a música precisou passar pela assertiva matemática para poder garantir o princípio básico do método preocupado em “[...] nada incluir em meus juízos que não se apresentasse tão clara e tão distintamente a meu espírito, que eu não tivesse nenhuma ocasião de pô-lo em dúvida" (DESCARTES, 1973, p. 45). Dessa forma, ao tomar o som como objeto, capaz de "[...] deleitar e provocar-nos paixões diversas" (DESCARTES, 2001, p. 55), o teórico o faz por acreditar se tratar de uma realidade mensurável. Nesse contexto, a música como um todo é tomada como passível de uma análise racional.

Como vimos acima, no âmbito epistemológico cartesiano ocorre nitidamente a subordinação do sensível à mathesis universalis, pondo o cogito como referência segura e inquestionável do sentido produzido pelo sujeito. É uma razão de tipo apodítico dedutivo que determina não só a linguagem em sentido epistemológico, mas também a própria noção de formação em sentido mais amplo, incluindo nela a educação da criança. Se Descartes se filia, a grosso modo, na longa tradição intelectualista da razão e do discurso racional como núcleo da educação da criança, contribuindo decisivamente para consolidá-lo na aurora da modernidade, Rousseau não pode aceitar tal discurso, uma vez que almeja, como núcleo de seu projeto de educação natural, uma "física experimental" que tem na escuta da melodia da natureza sua âncora principal. Nessa perspectiva, 
o "ouvir a voz da natureza ${ }^{11}$ " torna-se incompatível com o ouvir a voz da razão no sentido metódico experimental.

Nesse contexto, Rousseau precisou perpassar o paradigma da linguística cartesiana para justificar a ideia de música como paradigma da linguagem. Operou, portanto, com uma viragem fundamental: a linguagem, entendida como representação do cogito, que supunha serem as palavras instrumentos do conhecimento e que viria a justificar o caráter representativo da função da linguagem, foi substituída pelo primado rousseauniano das paixões como origem da linguagem, e não a razão. Estando as paixões na condição de primado fundamental, e não mais a razão, a música constituiu-se o paradigma da linguagem ${ }^{12}$.

Com esse enfrentamento, o genebrino põe em xeque não só uma teoria da linguagem, mas, sobretudo, a concepção de música que perpassa todo o classicismo francês. Com isso, a reposição da pergunta pela origem das línguas exigiu, a todo custo, o questionamento sobre a natureza da música e da forma como ela foi compreendida historicamente. A própria interpretação do conflito entre Rousseau e Rameau, que marcou um episódio determinante da estética e filosofia da música, precisa levar em conta a sólida herança cartesiana presente no Traité de L'harmonie de 1772, no qual é transparente a influência do Compendium Muciae de Descartes.

Enquanto conflito de racionalidades, o embate entre a harmonia de Rameau e a melodia de Rousseau configura a importância da matemática cartesiana enquanto matriz para formação do projeto moderno iluminista, bem como configura a necessidade de superação que a música teve em relação a um universo determinado em todos os sentidos pela razão. Nesse sentido, a noção de melodia carrega não só a novidade epistemológica proposta por Rousseau, mas também se constitui em um novo ideal formativo do ser humano, que, vertido ao universo infantil, significa, pedagogicamente, a necessária primazia a ser concedida aos sentidos e à razão perceptiva. Portanto, o que está em jogo nesse

11 Charles Taylor (1996, p. 619 et seq.) oferece uma das interpretações mais claras e atuais do significado rousseauniano da expressão "ouvir a voz da natureza", esclarecendo o modo como ela se conecta diretamente com seu sentido moral de "ouvir a voz do coração".

12 Para Prado Jr. (2008), a música ocupa, de fato, um lugar central na economia do Ensaio: ela se encontra, ao mesmo tempo, no ponto de partida da gênese ideal e em um dos polos da reflexão sistemática. E é esta presença, nestes dois polos, que dá a originalidade da teoria da linguagem em Rousseau e que o opõe, particularmente, a Condillac. No nível da origem, na identidade entre fala e canto, no nascimento da linguagem explicado pelas paixões, e não pelas necessidades, é a descontinuidade entre linguagem dos gestos e fala que é dada, a irredutibilidade do sentido à pura indicação. No nível da reflexão sistemática no privilégio concedido à melodia, é tanto a gênese quanto a estrutura da linguagem que são ordenados a um telos que não é o da Gramática, essa dimensão "harmônica" da linguagem. Em sua ambiguidade, ao longo do Ensaio, a música se apresenta como o paradigma segundo o qual a história e a essência da linguagem são pensadas. 
embate entre razão perceptiva e razão intelectual é um conflito epistemológico de racionalidades, o qual também assume repercussões pedagógicas diretas ao ideal formativo humano.

Com o poder imitativo da música, viu-se questionado o ideal representativo que as teorias racionalistas da linguagem reivindicaram. O caráter emblemático de uma revolução paradigmática do ponto de vista epistemológico caracterizou-se pela posição que a música passou a ocupar nas investigações a respeito da linguagem durante o século XVIII. Na perspectiva racionalista, prevalecia a ideia de que a ordem das palavras prescrevia a ordem dos pensamentos, e aquelas, por sua vez, tinham como função apresentar uma imagem da ideia, pois, “[...] servir-se de palavras [e] de outros sinais, combinando-os como fazemos [tem como objetivo] declarar aos outros nossos pensamentos" (DESCARTES, 2007, p. 94).

Já para o genebrino, "as primeiras histórias, as primeiras alocuções, as primeiras leis foram em verso: a poesia foi descoberta antes da prosa; [...] visto que as paixões falaram antes da razão" (ROUSSEAU, 2008, p. 146). O que há de peculiar aqui que estremece o edifício da linguística racionalista? A inversão de princípios fundamentais: as paixões são postas como anteriores à razão. Neste contexto, completa Rousseau: "o mesmo aconteceu com a música: a princípio não houve outra música além da melodia, nem outra melodia além do som diversificado da palavra [...]. Dizer e cantar eram outrora a mesma coisa [...]" (2008, p. 146). À arraigada concepção, não só de linguagem, mas à própria estrutura cartesiana da relação entre sujeito cognoscente e objeto cognoscível, bem como à razão como fonte do conhecimento, opõe-se a perspectiva rousseauniana. Tal perspectiva é anunciada pelo genebrino nas seguintes palavras: "[...] não se começou por raciocinar, mas por sentir. [...] A linguagem figurada foi a primeira a nascer, o sentido próprio foi o último a ser encontrado. [...] A princípio, falou-se somente em poesia; só se começou a raciocinar muito tempo depois" (2008, p. 103-105).

É nesse contexto que se fará possível a perspectiva rousseauniana, sustentando, em nosso ensaio, a justificação da hipótese de existência de uma racionalidade melódica capaz de articular o fazer musical no ocidente, com problemas filosóficos e formativos de ordem mais ampla. $\mathrm{O}$ genebrino precisou fazer entender que as necessidades arrancaram os primeiros gestos, e que as primeiras vozes foram arrancadas pelas paixões. Aqui se reconhece o primado segundo o qual a origem das línguas deve-se às necessidades morais e às paixões: "não foi a fome nem a sede, mas o amor, o ódio, a piedade, a cólera que [...] arrancaram as primeiras vozes. [...] Eis por que as primeiras línguas foram cantantes e apaixonadas antes de serem simples e metódicas" (ROUSSEAU, 2008, p. 104). 
Em conclusão, podemos afirmar que o núcleo da diferença de Rousseau em relação a Descartes repousa na centralidade atribuída às paixões e, por conseguinte, ao papel dos sentidos no âmbito da racionalidade humana. Precisamos investigar com mais cuidado, na sequência, em que sentido a melodia torna-se, aos olhos de Rousseau, o núcleo fundante da expressão musical, para posteriormente investigar a razão perceptiva como núcleo da educação natural. Ou seja, deixaremos nos guiar, no tópico seguinte, pela seguinte questão: qual é o estatuto da melodia no Ensaio?

\section{Da melodia como princípio}

Lê-se da seguinte maneira o título completo da obra em estudo: Ensaio sobre a origem das línguas: no qual se fala da melodia e da imitação musical. O subtítulo apresenta a centralidade da música para a discussão. Após considerar a origem da linguagem e colocar a música como princípio, o genebrino segue tematizando a origem da música e suas relações. Esta, por sua vez, liga-se às primeiras vogais que se formaram junto com as primeiras articulações ou sons, expressos a partir das paixões. Essa premissa básica sustenta o argumento central segundo o qual "[...] os primeiros discursos foram as primeiras canções [...]” (ROUSSEAU, 2008, p. 145); e justifica-se com a ideia de que ritmos, inflexões, melodias e acentos arrancados pelas paixões "[...] fizeram nascer, com a língua, a poesia e a música, ou melhor, que tudo isso não era outra coisa senão a própria língua [...]" (ROUSSEAU, 2008, p. 145). Enquanto crítica à concepção racionalista sobre a origem da linguagem, a antecipação das paixões em relação à razão conferiu as condições de antecipação originária da melodia.

A simbiose que o filósofo propõe na relação originária entre música e linguagem tem como principal objetivo mostrar que, no que diz respeito à origem, as duas foram uma coisa só. Tal preocupação exigiu, assim, a passagem pelo problema da relação entre melodia e imitação, na qual o papel dos sentidos adquire primazia. O filósofo pretende mostrar que as sensações, ao nos afetarem, não se reduzem a simples efeitos, mas podem ser compreendidas como sinais, imagens e efeitos morais e, para tornar claro esse ponto de partida, recorre à analogia entre pintura e música. Essa consideração, ao se levar em conta a macroestrutura do Ensaio, e de forma específica a novidade filosófica da teoria da linguagem rousseauniana, rompe com o racionalismo clássico de matriz cartesiana e sua decidida crença na força representativa da linguagem. 
Se há, de fato, em Rousseau, uma posição herética em relação à concepção iluminista de linguagem, esta reside em superar o paradigma da representação linguista pelo da imitação. Daí a centralidade da melodia. Ora, se, na pintura, é a imitação que dá vida e alma às cores; na linguagem, será o potencial imitativo da melodia o capaz de dar vida e alma às palavras. Imitar, portanto, não corresponde a representar. Mas, o que há na melodia que a torna capaz de redirecionar a concepção de linguagem da época a um novo conceito de linguagem e até mesmo de música? Demos ao próprio Rousseau o direito de resposta: "a melodia faz na música exatamente o que o desenho na pintura; é ela que representa os traços e as formas cujos acordes e sons são apenas cores" (2008, p. 150). Guarda-se, aqui, uma crítica contundente ao fazer artístico no âmbito da música e da pintura. Mas o que toca à musica sobre a problemática levantada em relação aos pintores?

Parece termos atingido o ponto do qual partimos anteriormente, anotado pela divisão sugerida pelo filósofo entre artes plásticas e ciências naturais. Mas, há algo que agora deve ser evidenciado, não apenas para corroborar as pretensões de nosso estudo, mas para justificar a contribuição do debate rousseauniano para a perspectiva epistemológica da época no que diz respeito à música: somente a imitação é capaz de elevar a música às belas-artes, não limitando-a ao âmbito das preocupações das ciências naturais. Nas palavras de Rousseau: "ora, o que é que faz da pintura uma arte de imitação? É o desenho. O que é que da música faz uma outra? É a melodia." (2008, p. 151).

Dada a importância da melodia e a maneira como ela determina o novo sentido do conceito de linguagem, bem como a posição basilar que esta passou a ocupar ao investir contra um problema epistemológico responsável por orientar a produção artística e do conhecimento em sentido mais amplo, fez-se necessário considerar a esfera oposta, principal representante da perspectiva racionalista em música: a harmonia. No que reside a beleza da harmonia e o que a garante? Quais seus limites na perspectiva rousseauniana?

Na verdade, a recusa de Rousseau a uma racionalidade harmônica precisará levar em conta o conceito de natureza e a posição que esse conceito ocupa em relação ao conjunto da obra do teórico. O conceito rousseauniano de natureza ${ }^{13}$

13 Não será interesse nosso discutir os diversos e contraditórios conceitos de natureza que perpassam a obra de Rousseau, contudo, para pontuarmos a importância de tal conceito para a modernidade e a obra do autor, faremos uso da consideração de Dalbosco (2011), ao afirmar que, para que o conceito de natureza de Rousseau possa se tornar, no entanto, um conceito eminentemente moderno, ele precisa se defrontar ao menos com um dos problemas de teodiceia, a saber: com o problema da origem da maldade na história da vida humana - poder mostrar que a sua culpa não reside em Deus nem exclusivamente no homem, mas sim na sociedade. Ele precisa mostrar, em primeiro lugar, que o sentido normativo do conceito de natureza não depende mais diretamente de 
extrapola nitidamente o significado físico-mecânico estabelecido a partir da física de Newton e da res extensa de Descartes. Ele carrega um sentido normativo de proveniência grega e romana, com raiz nitidamente estoica, vinculado principalmente ao pensamento de Sêneca. O núcleo desse sentido normativo é ético e cosmológico, pois a natureza é fonte da bondade e da beleza que reina no cosmo. Nesse sentido, "seguir a natureza" significa seguir a ordem universal que lhe é imanente, ou seja, seus ideais de bondade e beleza. Tudo o que é bom provém da natureza e compete ao ser humano se espelhar nela.

Daí a ideia de que "a beleza dos sons pertence à natureza" (ROUSSEAU, 2008, p. 153). Nessa perspectiva, a harmonia encontra-se em situação desfavorável, pois, para Rousseau, a beleza que esta expressa obedece a convenções, ao passo que agrada sempre a ouvidos habituados. Para chegar a essa conclusão o genebrino parte da teoria harmônica de Rameau desenvolvida no Traité d'Harmonie (1722), que já fora alvo de seus estudos em Chambéry, em 1735. Ouve-se de Rousseau: "o Sr. Rameau pensa que os registros mais altos de uma certa simplicidade sugerem naturalmente seus registros mais baixos e que um homem que possui ouvido, afinado e não exercitado, entoará naturalmente esse baixo" (2008, p. 154). O genebrino está convencido de que qualquer experiência básica com a música mostrará o contrário e de que os que jamais tivessem ouvido o baixo e a harmonia, em hipótese alguma os identificariam, e completa: "obrigados a ouvir tal estrutura harmônica desconhecida, a entenderiam como desagradável e optariam pelo simples uníssono" (ROUSSEAU, 2008, p. 154).

O que há de problemático aqui? O fato de a harmonia inviabilizar o princípio da imitação. Isso acontece quando a melodia é pensada em detrimento da harmonia e passa a ser estabelecida a partir de sucessões sonoras e regras de modulações, exigindo a precisão do desenvolvimento melódico. Nesse caso, embora exista uma preocupação melódica, ela se dá do ponto de vista racional e reflexivo, chegando a "[...] retirar-lhe a energia e a expressão, ela elimina o acento apaixonado para a ele substituir o intervalo harmônico, $[\ldots]$ ela separa [...] o canto e a palavra" (ROUSSEAU, 2008, p. 155). Nessas condições, a harmonia fere o princípio básico da origem das línguas ao inviabilizar o despertar das paixões, dos sentimentos ${ }^{14}$.

Deus para poder conectar, em seguida, a sua voz com a voz interna da consciência. De outra parte, para uma abordagem atual e bem fundamentada do conceito de natureza em Rousseau no âmbito anglo-saxônico, ver os estudos de Laurence D. Cooper (1999) e Frederick Neuhouser (2008, p. 109-133).

14 A posição acima confirma o partidário que foi Rousseau da melodiosidade da música italiana, que conferiu todo o pano de fundo para o desencadeamento da tão conhecida querele des bouffons entre 1752 e 1754. 
Com a emoção integrando o conjunto de objetivos da imitação musical, emerge a problemática sobre o que significa ser atingido pela música e sobre o que determina nossas impressões. Questiona-se, então, o primado da emoção causada pelos sons que excitam os nervos, uma vez que, nessa perspectiva, exclui-se todo o poder que a música exerce sobre os corações. Rousseau parte, portanto, da superação da mera sensação para firmar o princípio das impressões morais e afirma: "os sons, na melodia, não agem em nós apenas como sons, mas como sinais de nossas afeições, de nossos sentimentos; é assim que excitam em nós os movimentos que exprimem, e cuja imagem reconhecemos" (2008, p. 157). A reflexão nessa parte perpassa numa perspectiva antropológica o campo semântico da experiência com a música e reforça a tese de que toda e qualquer sensação musical possui sua origem em causas morais ${ }^{15}$.

Na verdade, como é próprio das ciências da natureza, todas as experiências são válidas universalmente. E a noção de música que tem como objeto o som, continha, em si, essa mesma perspectiva universalizante. Assim, as impressões, a partir da experiência com música, eram entendidas como efeitos sonoros sobre os corpos, ou sobre nervos, como prefere Rousseau. Ao se concentrar no campo semântico formado a partir de impressões morais, o filósofo relativiza toda e qualquer perspectiva universalizante em música e se mostra convencido que a experiência musical relativiza-se: "cada um é afetado somente por acentos que lhes são familiares; seus nervos agem na medida em que seu espírito os dispõe para isso [...]" (2008, p. 158).

No fundo, há um princípio fundamental nas entrelinhas que luta contra o conceito de razão iluminista: o sentimento. Afirmará o genebrino: “[...] não é tanto o ouvido que leva o prazer ao coração, mas sim o coração que o leva ao ouvido" (ROUSSEAU, 2008, p. 159). Essa máxima propõe uma inversão profunda ao passo que aponta os limites do julgamento da razão, seja na perspectiva do mais radical racionalismo, ou do mais radical empirismo. Quando o ouvido deixa de ser o condutor, é suspensa a validade racionalista segundo a qual os sentidos confirmam os conteúdos natos da ideia, bem como a crença empirista ferrenha nos conteúdos racionais adquiridos por meio dos sentidos. Dessa forma, o coração é posto como fonte, o movimento caracteriza-se ad interno, e a fonte primária deixa de ser pura razão.

Enquanto problema de época e racionalidade, o filósofo precisou enfrentar o que ele denomina de "[...] absurdo [das] observações físicas ocasionado no exame das belas-artes" (ROUSSEAU, 2008, p. 161). Ele refere-se aos mesmos

15 Para fazer-se entender, diz o genebrino: “[...] nossas mais emocionantes músicas são apenas um ruído sem valor para o ouvido de um caraíba [e acrescenta], serão seus nervos diferentes dos nossos?" (ROUSSEAU, 2008, p. 158). 
critérios adotados para análise do som e da luz ou cores: há uma falsa analogia aí. Essa é a suspeita do genebrino, a qual transparece na ideia de que "essa analogia foi logo rapidamente aceita sem nenhuma preocupação com a experiência ou a razão. O espírito de sistema misturou tudo e, sem saber pintar para as orelhas, decidiu-se cantar para os olhos" (2008, p. 161). Tais concepções contradizem as operações da natureza, tal como a concebia o genebrino, pois não leva em conta que a permanência é a característica fundamental das cores, enquanto a dos sons é a sucessão temporal: "o campo da música é o tempo, o da pintura é o espaço” (ROUSSEAU, 2008, p. 162).

Há uma recusa à difundida teoria de que, assim como as cores são determinadas pelo ângulo de refração do raio que as causam, também o som é determinado pelo número de vibrações do corpo sonoro em um determinado espaço de tempo. Para o filósofo, essa analogia é possível, desde que apoiada na pura razão, o que deixa de fora sentimentos e impressões morais. Ao tratar da pintura de sua época, irá caracterizá-la como inanimada e como algo que certamente produz uma experiência estética e pode transportar alguém a lugares diversos, mas ainda assim não é correlata à da música. Com a música, todo e qualquer sinal vocal nos indica a existência de um semelhante. Daí a conclusão de que somente o homem canta, o que nos liga à definição de abertura do Ensaio: "a palavra distingue os homens dos animais" (ROUSSEAU, 2008, p. 97). Já foi de Aristóteles a definição de que o homem é o animal que possui o logos; em Rousseau, essa definição se amplia ao passo que o que define o ser humano é a palavra cantada.

Ao chegar a esta altura de nossa reconstrução do Ensaio, já estamos em condições de resumir o essencial que interessa ao nosso ponto em discussão. $\mathrm{O}$ Ensaio contém uma novidade filosófica na teoria rousseauniana de linguagem na medida em que rompe com o modelo linguístico da mente representacional (modelo da representação sígnica), colocando em seu lugar o papel imitativo da linguagem. Isso foi possível porque Rousseau distanciou-se da certeza apodítica do cogito, reposicionando o papel das paixões e emoções no âmbito da cognição humana. Nesse contexto, concedeu primazia, no âmbito da música, à melodia em detrimento ao papel atribuído pelos racionalistas à harmonia. Tomamos reconstrutivamente tal procedimento do Ensaio para exemplificar a ruptura de seu pensamento em relação ao racionalismo cartesiano. Na sequência, na última parte de nosso ensaio e como forma de conclusão deste, vamos tratar de alguns desdobramentos pedagógicos que se vinculam à concepção musical rousseauniana. Esse passo de nossa análise exige considerar o Emílio. 


\section{Da racionalidade melódica à experiência formativa natural}

Nas entrelinhas do Ensaio está presente uma problemática epistemológica que se tornará muito explícita na arquitetônica pedagógica do Emílio. Tal problemática sustenta, também, no âmbito da educação natural, a experiência formativa do aluno fictício. Esse é o ponto que gostaríamos de tratar na sequência, começando pela explicitação da própria problemática epistemológica.

O tema de fundo que cruza o Emílio do começo ao fim é a crítica de Rousseau à éducation barbare. No século XVIII, se consolida uma noção racionalista de educação que remonta à tradição grega, de matriz tanto platônica como aristotélica. O racionalismo platônico que nos interessa aparece nitidamente, de maneira especial, nos Diálogos Fedão e Menão, caracterizando-se, entre outros, pelos seguintes aspectos: a) distinção entre inteligível e sensível; b) admissão das ideias (formas) e de seu caráter eterno e inato; c) a crença na imortalidade da alma; d) a defesa da teoria do conhecimento como anamnese e; e) a noção de ensino e aprendizagem como o extrair ou o fazer brotar de dentro. Todos esses aspectos justificam a tese central do racionalismo platônico - isto é, do Platão da maturidade - de que o pensamento puro é determinado pelo mundo das ideias e, portanto, pelo inteligível.

Embora existam enormes diferenças entre Platão e Aristóteles, o racionalismo platônico acima exposto é assumido pelo estagirita no Livro XII (Lambda) da Metafísica. Aristóteles assume aí a tese de que o pensamento puro (o intelecto) é determinado pelo inteligível e, ao tornar-se independente dos sentidos, tem condições de conhecer as coisas como elas são em si mesmas. Com isso, se expressa o núcleo de uma vertente do racionalismo aristotélico: o inteligível que move o intelecto é a substância primeira (prôtê ousia), a qual ocupa o lugar mais alto na coluna de opostos e é, enquanto tal, simples, existindo em ato (Met, 1072a 30, ARISTÓTELES, 1995). No contexto desse mesmo livro da Metafísica, fica estabelecida a vida contemplativa como melhor maneira do intelecto ser afetado pelo inteligível (Met, 1072b 20, ARISTÓTELES, 1995).

Portanto, por meio da vida contemplativa o intelecto é afetado pelo inteligível e pensa sobre o mundo. É esse núcleo duro da tradição racionalista ocidental que chega até o racionalismo moderno, especialmente até Descartes. Obviamente que se não podemos considerar Aristóteles como um mero continuador de Platão ${ }^{16}$, também não podemos inserir a filosofia cartesiana simplesmente

16 O livro sete da Metafísica investiga um sentido de substância que se distancia da ontologia platônica. Além disso, como mostrou Marco A. Zingano (1998, p. 31 e 170), no De Anima, Aristóteles desenvolve uma teoria do intelecto que não é mais receptiva das formas inteligíveis, 
na tradição platônica e aristotélica. Nesse sentido, o cogito é iminentemente moderno porque põe a subjetividade como centro e referência do pensamento filosófico de modo completamente original, isto é, de uma maneira que não foi vista pela tradição passada. Contudo, com a primazia concedida à coisa pensante, Descartes assume o núcleo duro daquele racionalismo, vendo agora a atividade do cogito como fonte doadora de sentido das coisas e do mundo.

Esse breve apanhado já é suficiente para dirigirmo-nos novamente a Rousseau, o qual põe a razão perceptiva no centro de seu projeto de educação natural, criticando, por um lado, a primazia da razão intelectual e, por outro, a obcecação da educação de sua época em querer raciocinar com as crianças. Ao fazer isso, ele está se distanciando não só daquela tradição racionalista, da qual Descartes é o principal representante moderno, mas também do intelectualismo pedagógico a ela inerente. Nesse contexto, torna-se decisivo expor e analisar a distinção rousseauniana entre razão perceptiva e razão intelectual. Começamos pela citação integral da passagem do Emílio que trata do tema. Assim se expressa Rousseau:

Como tudo que entra no conhecimento humano entra pelos sentidos, a primeira razão do homem é uma razão perceptiva. Ela é que serve de base à razão intelectual: nossos primeiros mestres de filosofia são os nossos pés, nossas mãos, nossos olhos. Substituir tudo isso por livros não é ensinar-nos a raciocinar, é ensinar-nos a nos servirmos da razão de outrem; é ensinar-nos a acreditarmos muito e a nunca sabermos coisa alguma (ROUSSEAU, OC IV 370; 1992, p. 121).

Há dois aspectos dessa passagem que interessam diretamente ao nosso ponto. $\mathrm{O}$ primeiro refere-se propriamente à distinção entre as duas razões citadas: enquanto a perceptiva brota dos sentidos e corresponde à educação adequada dos mesmos, a intelectual tem a ver com o emprego adequado do raciocínio. Rousseau atribui nitidamente uma tarefa educativa para ambas: à razão perceptiva correspondem o fortalecimento do corpo e o refinamento dos sentidos; à intelectual, a capacidade de pensar por si mesmo. Contudo, de acordo com a arquitetônica pedagógica do Emílio, razão perceptiva e razão intelectual implicam-se mutuamente, do mesmo modo que, sem a educação natural, não seria possível pensar na educação moral e na educação política. $\mathrm{O}$

uma vez que o intelecto é concebido como atividade própria que produz seus próprios objetos, estabelecendo, com isso, outra forma de relação com o inteligível. 
segundo aspecto refere-se à crítica ao intelectualismo pedagógico e, com ele, à educação livresca, que está subjacente à passagem citada. A distinção clara entre razão perceptiva e razão intelectual e o emprego adequado delas, considerando o estágio em que se encontra o educando, são decisivos à formação do pensamento autônomo. Em síntese, a tese de fundo que sustenta a distinção entre razão perceptiva e razão intelectual é a de que o fortalecimento do corpo e o refinamento dos sentidos é condição de possibilidade "às operações simples e seguras do espírito" (ROUSSEAU, 2008).

$\mathrm{O}$ fato de ter recorrido à razão perceptiva não significa que Rousseau estivesse apelando simplesmente às sensações e que depositasse nelas o alicerce da moralidade e do conhecimento. Duas considerações nos auxiliam a esclarecer melhor isso: a primeira é de conteúdo estritamente epistemológico; a segunda, de caráter moral. Do ponto de vista epistemológico, Rousseau está certo de que - e isso será desenvolvido sistematicamente depois por Kant -, embora nosso conhecimento comece com a experiência, não pode ser por ela justificado. Ou seja, sua crítica ao predomínio da razão intelectual não significa obviamente a dispensa da atividade intelectiva como fonte sintetizadora do conhecimento. Ao negar o poder absoluto da razão analítica de cunho dedutivo (demonstrativo), ele enfatiza o âmbito da experiência como ponto de partida da elaboração do conhecimento. Essa mudança no ponto de partida terá implicações ainda maiores, como veremos abaixo, à questão especificamente educacional e, com ela, à aprendizagem da criança. Contudo, o primado da razão perceptiva ocorre do ponto de vista da gênese (ponto de partida) da aprendizagem e não significa obviamente a dispensa da razão intelectual.

Do ponto de vista moral, a ênfase à razão perceptiva refere-se à importância das emoções e das paixões na constituição da moralidade. Nesse aspecto, Rousseau insere-se nitidamente na tradição inglesa da filosofia dos sentimentos morais, cuja síntese bem elaborada é a obra Teoria dos sentimentos morais de Adam Smith (2002), a qual serve de fonte de inspiração para que Rousseau critique o intelectualismo moral e ponha no coração, ou seja, nas emoções e paixões humanas, a fonte da moralidade. Ora, é justamente no âmbito dessa problemática que encontramos o elo direto entre Ensaio e Emílio, pois a primazia concedida à melodia em relação à harmonia tendo em vista recobrar as paixões como núcleo dos sentimentos morais coaduna-se com a centralidade concedida, no Emílio, aos sentimentos que brotam do coração como fonte da educação moral dirigida ao jovem Emílio.

Uma vez esclarecidos os principais motivos que levam Rousseau a conceder prioridade à razão perceptiva e também os limites de tal concessão, 
resta-nos agora analisar especificamente os desdobramentos pedagógicos que emergem de tal prioridade. Ou seja, precisamos nos ocupar, agora, brevemente e já em forma de conclusão, com a questão do vínculo entre razão perceptiva e educação natural.

Quando nos referimos à educação natural em Rousseau, precisamos ter presente que ela se insere, no Emílio, em uma arquitetônica pedagógica mais ampla, da qual faz parte também a educação moral e a educação política. Enquanto a educação natural refere-se à formação do aluno fictício em sua fase inicial, compreendendo uma noção tripartite de infância (primeira, segunda e terceira infâncias), a educação moral e a política dizem respeito à juventude e à fase adulta do Emílio. Embora cada fase tenha suas especificidades, elas formam o projeto educativo como um todo, cuja meta, como Rousseau enfatiza, consiste em formar o ideal do ser humano, com "a razão de um sábio e o vigor de um atleta” (ROUSSEAU, OC IV, 362; 1992, p. 113).

Considerando essa arquitetônica pedagógica, o primado da razão perceptiva torna-se nuclear à educação natural. É nesse âmbito que Rousseau desenvolve o princípio pedagógico da educação pelas coisas, pois acredita que a melhor forma de preparar solidamente o futuro desenvolvimento cognitivo e moral do aluno fictício é estimular previamente seu desenvolvimento corporal e sensitivo. Também é por isso que se dá, nos três primeiros livros do Emílio, o desenvolvimento de inúmeras estratégias pedagógicas visando fortalecer o corpo e refinar os sentidos do aluno fictício. Trata-se, portanto, de um amplo movimento pedagógico ancorado na razão perceptiva, fazendo parte do credo pedagógico rousseauniano mais amplo de que a inserção direta da criança no ambiente natural, além de evitar os riscos de corrupção do mundo adulto, prepara a criança à formação futura de seu caráter moral.

Em síntese, como podemos observar, com o primado concedido à razão perceptiva na infância, implicam-se motivos não só de ordem epistemológica, mas também moral. Ora, encontramos aqui, no Emílio, pelo viés pedagógico, uma ressonância clara do primado concedido às paixões no âmbito do Ensaio. Da educação natural centrada na razão perceptiva brota então um tipo de experiência formativa que tem seu centro no refinamento dos sentidos, o qual exige tanto a inserção do educando no ambiente natural como o aprendizado tenso e progressivo do domínio de suas próprias paixões. Nesse contexto, o apelo ao primado melódico da música pode ser visto também como uma fonte genuína da dupla tarefa formativa, ou seja, do refinamento dos sentidos e do progressivo domínio das paixões. 


\section{REFERÊNCIAS}

ARENDT, H. Zwischen Vergangenheit und Zukunft. Übungen im politischen Denken I. München/Zürich: Piper, 1994.

ARISTÓTELES. Philosophische Schriften in sechs Bänden. Hamburg: Meiner, 1995.

COOPER, L. D. Rousseau: Nature and the Problem of the Good Life. Pennsylvania: The Pennsylvania State University Press, 1999.

DALBOSCO, C. A. Educação natural em Rousseau: das necessidades da criança e dos cuidados do adulto. São Paulo: Cortez, 2011.

DESCARTES, R. Compendio de Música. Tradução: Primitiva Flores e Carmen Gallardo. Madrid: Tecnos, 2001.

. Discurso do Método. São Paulo: Martins Fontes, 2007.

. Discurso do Método. Tradução: J. Guinsburg e Bento Prado Júnior. São Paulo: Abril Cultural, 1973. p. 33-150 (Os pensadores, v. XV).

DURKHEIM, E. Educação e sociologia. São Paulo: Edições Melhoramentos, 1975.

FOUCAULT, M. A hermenêutica do sujeito. São Paulo: Martins Fontes, 2004.

GADAMER, H.-G. Gesammelte Werke 1. Hermeneutik I. Tübingen: Mohr Siebeck, 1999.

HABERMAS, J. Nachmetaphysisches Denken. Philosophische Aufsätze. Frankfurt am Main: Suhrkamp, 1997.

MARQUES, J. O. A. Rousseau, Rameau e o Ensaio sobre a origem das línguas. In: I Jornada de Estudos J.-J. Rousseau. Departamento de Filosofia da USP, 24 a 26 de março de 2010. Disponível em: <http://www.unicamp.br/ jmarques/pesq/ensaio.htm $>$. Acesso em: 22/12/2013.

NEUHOUSER, F. Rousseaus Theodicy of 'Amour Propre': Evil, Rationality and the Drive for Recognition. Oxford, 2008.

NIETZSCHE, F. W. O nascimento da tragédia. Tradução: J. Guinsburg. Rio de Janeiro: Companhia das Letras, 1993.

. O drama musical grego. In: . A visão dionisíaca do mundo e outros textos de juventude. Tradução: Marcos Sinésio Pereira Fernandes e Maria Cristina dos Santos de Souza. São Paulo: Martins Fontes, 2005.

PRADO JR., B. A força da voz e a violência das coisas. In: ROUSSEAU, J.-J. Ensaio sobre a origem das línguas. Tradução: Fulvia M. L. Moretto. 3. ed. Campinas, SP: Editora da Unicamp, 2008.

RAMEAU, J. P. Démonstration du principe de l'harmonie servant de base à tout l'art musical théorique \& pratique. Paris: Durand, Pissot, 1750. 
ROUSSEAU, J. J. Émile. Éducation-Morale-Botanique. Paris: Gallimard, Bibliothèque de la Pléiade, 1969. (Sigla: OC IV)

. Emílio ou da Educação. Rio de Janeiro: Bertrand Brasil, 1992.

. Ensaio sobre a origem das línguas. Tradução: Fulvia M. L. Moretto. 3. ed. Campinas, SP: Editora da Unicamp, 2008.

SCHNEIDERS, W. Das Zeitalter der Aufklärung. München: Verlag C. H. Beck, 2008.

SMITH, A. Teoria dos sentimentos morais. São Paulo: Martins Fontes, 2002.

TAYLOR, C. Quellen des Selbst. Die Entstehung der neuzeitlichen Identität. Frankfurt am Main: Suhrkamp, 1996.

WEBER, M. Os fundamentos racionais e sociológicos da música. Tradução: Leopoldo Waizbort. São Paulo: EDUSP, 1995.

ZINGANO, M. Razão e sensação em Aristóteles. Um ensaio sobre De Anima III 4-5. Porto Alegre: L\&PM, 1998.

Texto recebido em 04 de abril de 2014. Texto aprovado em 22 de julho de 2014. 
